\title{
Characterization of Aerosol Emission from Single-film Rupture in a Tube
}

\author{
Sheng-Hsiu Huang1, Yu-Mei Kuo ${ }^{2 *}$, Chih-Wei Lin ${ }^{1}$, Po-Chin Chen ${ }^{1}$, Chih-Chieh Chen ${ }^{1}$ \\ ${ }^{1}$ Institute of Environmental and Occupational Health Sciences, College of Public Health, National Taiwan University, \\ Taipei 10055, Taiwan \\ ${ }^{2}$ Department of Occupational Safety and Health, Chung Hwa University of Medical Technology, Tainan 71703, Taiwan
}

\begin{abstract}
The generation of aerosols during "silent" tidal breathing via the bronchiole fluid film burst (BFFB) mechanism, which involves the rupturing of mucus meniscus or film in terminal bronchioles, has been described in recent studies. To replicate the BFFB mechanism and identify the characteristics of aerosol generation during normal breathing, this study set up a single-film generation system employing tubes ranging from 0.7 to $2.94 \mathrm{~cm}$ in diameter that simulated the bronchioles. A liquid film of artificial mucus or soap solution was applied on the bottom of each tube and moved upward by filtered carrier air, which eventually led to the rupturing of the film. The resultant airborne particles $(>7 \mathrm{~nm})$ were then counted with a condensation particle counter, and the number size distributions $(0.6-20 \mu \mathrm{m})$ were measured with an Aerodynamic Particle Sizer. The experimental results show that the film's rising velocity, rise distance and surface tension in addition to the tube diameter all affected the total particle count and the size distribution. The total particle count increased with the rising velocity until the latter reached $3 \mathrm{~cm} \mathrm{~s}^{-1}$ and then decreased as the velocity continued growing-a phenomenon that was mainly due to the curvature of the film increasing with the velocity. Moreover, the larger the tube diameter, the higher the particle count. When a $0.9 \% \mathrm{NaCl}$ solution was added to increase the surface tension of the film, the total particle count decreased as the surface tension increased, regardless of whether artificial mucus or soap solution was used. This approach to reducing the propagation of infectious diseases in healthcare facilities seems to merit further exploration.
\end{abstract}

Keywords: Bronchiole fluid film burst; Film aerosols; Rising velocity; Surface tension.

\section{INTRODUCTION}

Coughing and sneezing are known to spread respiratory diseases. The aerosol outputs by coughing and sneezing are visible because of the high number concentration and large size (in the micrometer range). Although coughing and sneezing can be loud and irritating to people around, they do alert people to stay away from sources of bioaerosols. In contrast to these audible and visible aerosol generation mechanisms, generation of aerosols by "silent" tidal breathing has also been reported in recent studies (Papinen and Rosenthal, 1997; Fabian et al., 2008; Chao et al., 2009; Morawska et al., 2009). Such aerosol generation might play a more important role in disease transmission, especially in intensive care and emergency care facilities. The speculated aerosol generation mechanism was bronchiole fluid film burst, BFFB (Morawska et al., 2009; Almstrand et al., 2010;

\footnotetext{
* Corresponding author.

Tel.: 886-2-33668086; Fax: 886-2-23938631

E-mail address: ymkuo@mail.hwai.edu.tw;

kuoyumei@gmail.com
}

Holmgren et al., 2010; Schwarz et al., 2010; Fabian et al., 2011). In addition, alveolar pores that open on lung expansion may also be a source of aerosols in exhaled breath (Oldham and Moss, 2019).

Aerosol generation from film bursting is probably the most important transfer mechanism of hazardous materials from a liquid body into the atmosphere (Pilacinski et al., 1990; Kuo and Wang, 2002; Hung et al., 2010). However, films are normally in the form of bubbles. Aerosol emission from bubble bursting has been extensively studied, with particular focus on marine aerosols generated from bursting of single bubbles (Blanchard and Syzdek, 1988; Afeti and Resch, 1990; Lhuissier and Villermaux, 2012; Modini et al., 2013). It was found that the size and number of film droplets per bubble increased with bubble size (Afeti and Resch, 1990; Resch and Afeti, 1991, 1992). Moreover, measurements conducted by Spiel (1998) demonstrated that the average size of film droplets increased with bubble size and no film droplets were generated from seawater bubbles smaller than $2.4 \mathrm{~mm}$.

When a bubble ruptures, the rupture thickness of bubble film is governed by liquid properties of the bubbling solution, making particle size a consequence of solution composition (Russell and Singh, 2006). Resch et al. (1986) 
found that the rupture thickness was affected by bubble size and surface tension. Several studies demonstrated that aerosol production was strongly affected by the solution properties, in particular, surface tension (Afeti and Resch, 1990; Russell and Singh, 2006; Bird et al., 2010). Our previous study demonstrated that the mass of emitted particles per bubble increased with decreasing surface tension and increasing solute volume concentration ( $\mathrm{Ke}$ et al., 2017).

The BFFB relies on the physiology and physics of breathing. During exhalation, airway closure takes place in the vicinity of terminal bronchioles, creating a plug of respiratory tract lining fluid. When the bronchioles reopen and distend during the subsequent inhalation, a film across the passage forms. Finally, droplets may generate as this film ruptures (Morawska et al., 2009). As a liquid film travelling along a tube, the volume of the liquid film decreases due to the fluid adherence to the inner wall of the tube (Halpern et al., 1998; Espinosa and Kamm, 1999) and liquid evaporation (Champougny et al., 2018) until it reaches a minimum thickness. Eventually, thickness instabilities due to surface concentration heterogeneities of surfactants can develop (Bergeron, 1997) stochastically through the bubble cap (Lhuissier and Villermaux, 2012) and lead to locally interfacial spots, which are very fragile and prone to burst (Vrij, 1964; Vrij and Overbeek, 1968; Lhuissier and Villermaux, 2009). The life span of a rising liquid film mainly depends on both the drainage dynamics and instability mechanisms that trigger the film bursting (de Gennes, 2001; Rio and Biance, 2014).

In contrast to previous extensive studies on aerosol emission from bubble bursting at the open liquid surfaces, experimental data on aerosol emission from film bursting in the tube, such as BFFB in terminal bronchioles, are limited. With a focus on the BFFB, the main objective of the present study is to characterize aerosol emission from film bursting using a single-film generation system. The purge time and dwell time of the test system were first identified to set the upper limit of film rise distance, defined as the height from the bottom of the tube to where the rising film ruptures in the tube. Rise distance of the film, film rising velocity, surface tension and viscosity of the solution were among the major operating parameters. The ultimate goal is to further understand the mechanisms and characteristics of BFFB in the respiratory tract, so as to mitigate the exhaled aerosol particles, which might be an important source of infection.

\section{METHODS}

\section{Single-film Generation and Particle Measuring System}

The setup of the experimental single-film generation system is shown in Fig. 1. A glass tube with a fixed length of $30 \mathrm{~cm}$ but different diameters was adopted to accommodate the film. A hybrid linear actuator (21000 Series Stepper Motor; Haydon Kerk Motion Solutions Inc., Waterbury, CT, USA) was employed to raise the reservoir of the test solution to touch the bottom of the tube to form the film, and then lower the reservoir to trigger the open switch of HEPAfiltered air. The incoming air pushed the film up the tube. While rising, the film lost liquid to the wall, became thinner, and eventually ruptured, because the thinning film was no longer strong enough to maintain the film structure. The aerosol output from the ruptured film was carried by the filtered air into the chamber $\left(10 \times 10 \times 6.5 \mathrm{~cm}^{3}\right)$, to be further dried by the make-up air. The aerosol particles were then measured by an Aerodynamic Particle Sizer (APS; Model 3321A; TSI Inc., St. Paul, MN, USA) and a condensation particle counter (CPC; Model 3022, TSI Inc.). The APS measured aerosol number concentration and size distribution ranging from 0.6 to $20 \mu \mathrm{m}$, while the CPC counted the aerosol number concentration of particles larger than $7 \mathrm{~nm}$.

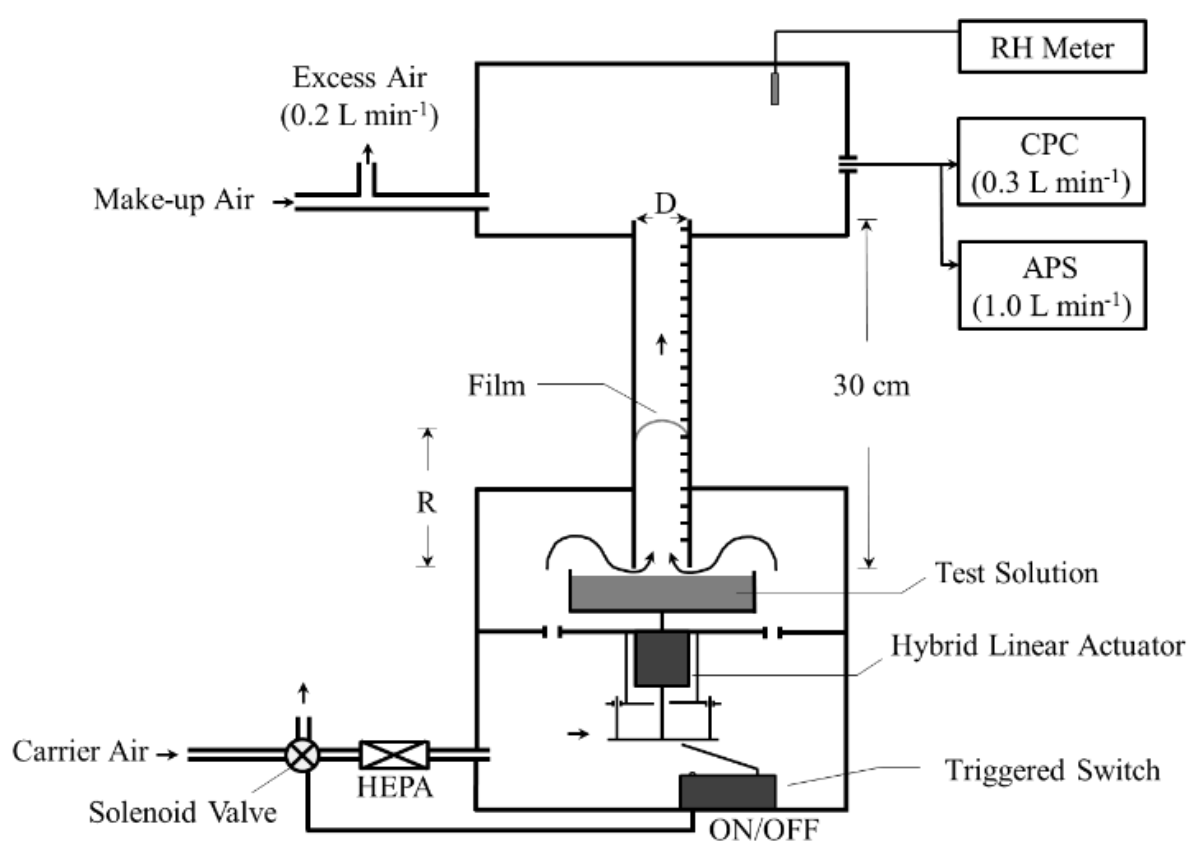

Fig. 1. Schematic diagram of experimental system setup for single-film generation. 
The sampling flow of APS and CPC was $1.0 \mathrm{~L} \mathrm{~min}^{-1}$ and $0.3 \mathrm{~L} \mathrm{~min}^{-1}$, respectively, with only the core flow used. To prevent contamination of the chamber by outside air, the excess air flow was maintained around $0.2 \mathrm{~L} \mathrm{~min}^{-1}$ by adjusting the make-up air flow according to the carrier air flow. The list and ranges of operating parameters are shown in Table 1. Tube diameters ranging from 0.7 to $2.94 \mathrm{~cm}$ were used to simulate the bronchioles of the respiratory tract. Tubes smaller than $0.7 \mathrm{~cm}$ were difficult to manipulate and hence not considered in the present study, although the terminal bronchioles, with diameter normally around 0.5 $\mathrm{mm}$ or less (Yeh and Schum, 1980), were most likely to generate BFFB aerosols.

\section{Test Solutions and Operating Parameters}

Mucus is the principal fluid in the respiratory tract, but its surface tension varies with different amount of surfactant generated. Therefore, sodium dodecyl sulfate (SDS) solution was employed to adjust the surface tension of mucus. The artificial mucus was prepared using locust bean gum according to a previous study (Anwarul Hasan et al., 2010). The viscosity of SDS solutions of different concentrations remained almost unchanged at $0.09 \mathrm{P}$. The viscosity of mucus reduced from 3.45 to $0.45 \mathrm{P}$ when diluted with soap solution. The film rising velocity in the tube was determined by both carrier air flow and tube diameter. Considering the reported air velocity of $5 \mathrm{~cm} \mathrm{~s}^{-1}$ in terminal bronchiole (Hinds, 1999), the test film rising velocity varied from 1 to $15 \mathrm{~cm} \mathrm{~s}^{-1}$ including $1,2,2.5,2.8,3,4,6,9,12$, and $15 \mathrm{~cm} \mathrm{~s}^{-1}$. The rise distance was more complicated and mainly affected by the purge time of the whole system, including tube diameter, carrier air flow, solution concentration, chamber size, and frequency of bubble generation, i.e., the dwell time. The studied rise distance varied from 3 to $7 \mathrm{~cm}$ including $3,4,5$, 6 , and $7 \mathrm{~cm}$. One film generates only a limited number of aerosol particles. In order to have consistent statistics, aerosol particles from a total of 30 ruptured films were collected for each measurement and each condition was repeated at least 30 times. The temperature and relative humidity in the test chamber were monitored using a thermo-hygrometer (HygroPalm HP22; Rotronic AG, Grindelstrasse, Switzerland). The surface tension was measured using a meter (DST-30; Surface Electro Optics Co., Ltd., Korea), and the viscosity was measured using a viscometer (LVT; Brookfield Engineering Laboratories Inc., Middleboro, MA, USA).

\section{RESULTS AND DISCUSSION}

\section{Single-film Rupture in a Tube}

The complete cycle of aerosol count measured as a function of time is shown in Fig. 2, for the case of soap solution, surface tension of 27 dyne $\mathrm{cm}^{-1}$, viscosity $0.09 \mathrm{P}$, and tube diameter of $2.65 \mathrm{~cm}$. The purge time started with the stepping motor movement. It took about $10 \mathrm{~s}$ from forming the film right at the bottom of the tube to lowering the solution reservoir to sit on the hybrid linear actuator (Fig. 1) and then activating the filtered air to lift the film. The rise distance of the film in the tube and the time needed to burst is determined by several parameters, including tube diameter, air flow and dwell time. The survival time of the film, i.e., the time it remained in the tube, ranged from 0.5 to $7 \mathrm{~s}$. The peak aerosol count from this low-surface-tension soap film in the largest tube of $2.65 \mathrm{~cm}$ was around 200 \# at $50 \mathrm{~s}$. After film bursting, it took about $100 \mathrm{~s}$ to ventilate out all the aerosols remaining in the dilution chamber. The rule of thumb is that purging can be considered complete when the aerosol counter shows zero for at least 10 s continuously.

The carrier air flow was varied to provide different film rising velocities. The total sampling flow was fixed at $1.3 \mathrm{~L} \mathrm{~min}^{-1}: 1 \mathrm{~L} \mathrm{~min}^{-1}$ for APS and $0.3 \mathrm{~L} \mathrm{~min}{ }^{-1}$ for CPC. Thus, the carrier air could be a distinct fraction of the total sampling flow for the cases of high rising velocities. As shown in Fig. 3, with the case of soap solution, surface tension of 27 dyne $\mathrm{cm}^{-1}$, viscosity of $0.09 \mathrm{P}$, tube diameter of $2.65 \mathrm{~cm}$ and 30 replicates, the purge time decreased with increasing film rising velocity. The longest purge time was used as the operating purge time to assure that the tube and the chamber downstream were aerosol free. When rising velocity increased from 1.2 to $15 \mathrm{~cm} \mathrm{~s}^{-1}$, the purge time decreased from 180 to $80 \mathrm{~s}$. However, for smaller tubes and lower rising velocities, the purge time was dominated by the make-up air flow.

The rise distance could affect the aerosol counts from film bursting as discussed below. Thus, it was essential to control the rise distance so the film ruptured at the same height. When the experiment began, the inner wall of the tube was dry to initiate the first film generation. If the dwell time between two film generations was too short, the film would rise high. As shown in Fig. 4, when the dwell time was set at $20 \mathrm{~s}$, the rise distance was $30 \mathrm{~cm}$, indicating that the film burst right on the upper edge of the tube. However, $20 \mathrm{~s}$ was far shorter than the purge time required (100 s) to vent out all the residual droplets. Therefore, in addition to the purge time of the film generation system, the dwell time between two film generations should be set longer than the purge time to avoid contamination from residual aerosols in the chamber. This limitation restricted the time that the film stayed in the tube, corresponding to the rise distance, as shown in Fig. 4. In order to keep the dwell time longer than the purge time, the rise distance was set at $7 \mathrm{~cm}$ for most of the cases tested. In the present case, the dwell time was $150 \mathrm{~s}$.

Table 1. Operating parameters and ranges.

\begin{tabular}{lll}
\hline Solution & Soap & Mucus \\
\hline Rise distance $(\mathrm{L}, \mathrm{cm})$ & $3,4,5,6,7$ & 7 \\
Rising velocity $\left(\mathrm{V}, \mathrm{cm} \mathrm{s}{ }^{-1}\right.$ ) & $1,2,2.5,2.8,3,4,6,9,12,15$ & 3 \\
Tube diameter (D, cm) & $0.7,1.16,1.86,2.65,2.94$ & 2.65 \\
Surface tension (s, dyne cm ${ }^{-1}$ ) & $50,45,40,35,27$ & $60,49,43,36$ \\
Viscosity (v, P) & 0.09 & $0.45,0.8,1.6,3.45$ \\
\hline
\end{tabular}




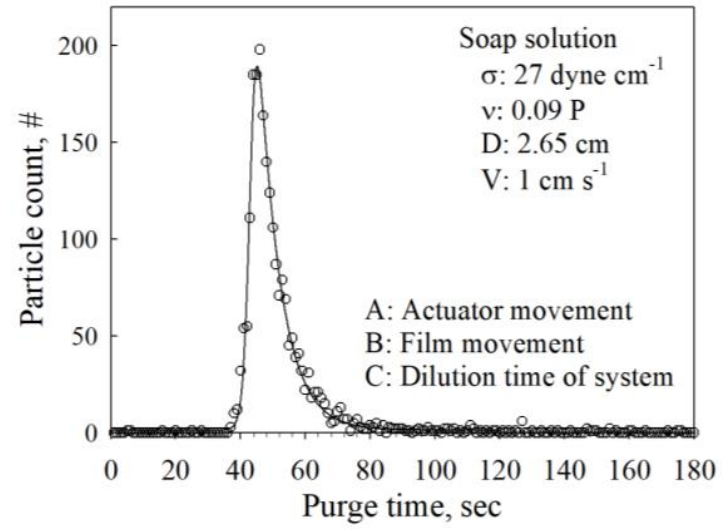

Fig. 2. Definition of purge time from single-film bursting.

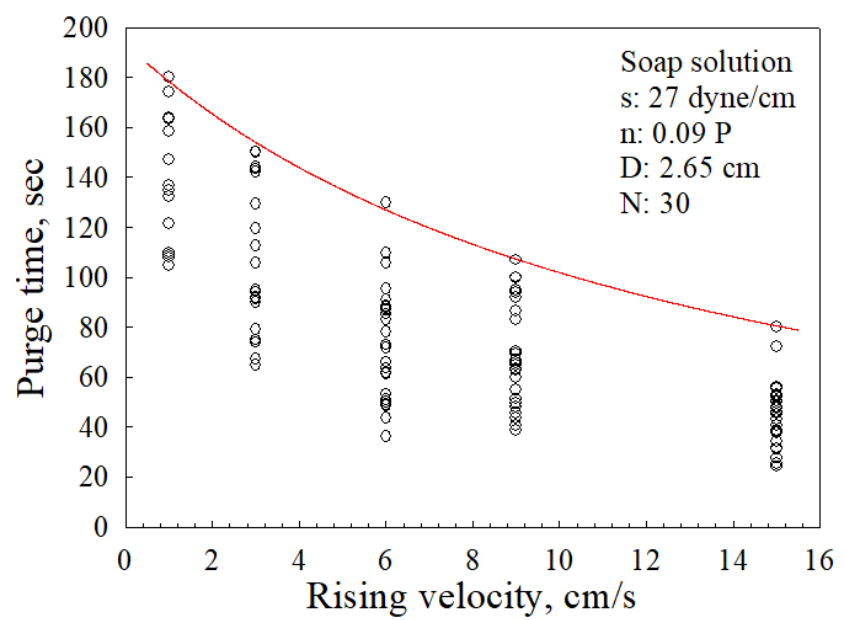

Fig. 3. Purge time of single-film bursting at different air velocities.

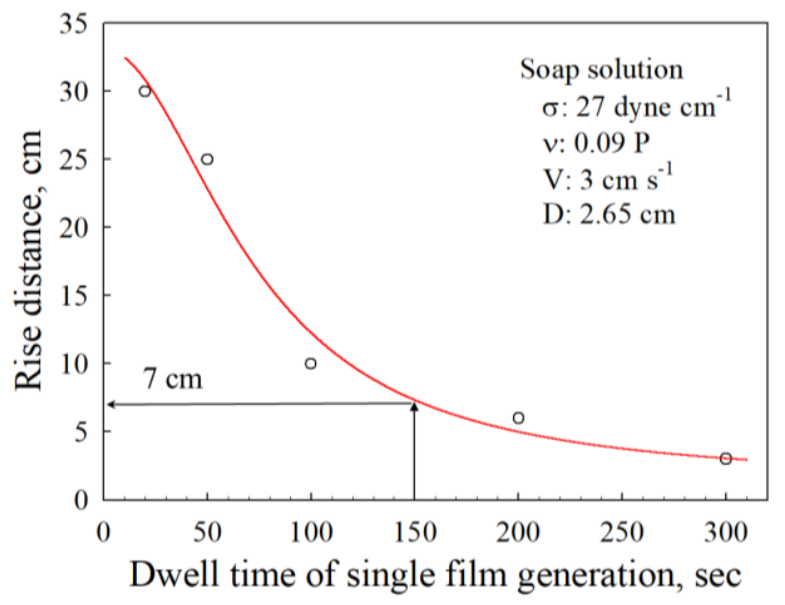

Fig. 4. Rise distance as a function of dwell time.

\section{Effect of Rise Distance on Single-film Aerosols}

The total aerosol count generated from a film bursting increased with increasing rise distance, as shown in Fig. 5, for soap solution, surface tension of 27 dyne $\mathrm{cm}^{-1}$, viscosity of $0.09 \mathrm{P}$, and tube diameter of $2.65 \mathrm{~cm}$, rise velocity of $3 \mathrm{~cm} \mathrm{~s}^{-1}$, and 800 replicates. The error bar represented one standard deviation of $\mathrm{N}$ (800 in this figure) measurements. The postulation was that droplets generated inside the tube had more time to be dried by the carrier air when dropping under gravity if the rise distance was high enough. The increasing trend became even more obvious as shown by the increasing slope, indicating that if the rise distance was not high, a large portion of the generated droplets did not have enough time to get dried, be carried into the chamber, and then counted by the aerosol instruments. The aerosol size distribution as a function of rise distance is shown in Fig. 6. Not only did the number count increase with increasing rise distance, as shown in Fig. 5, the count median diameter (CMD) also became larger, while the geometric standard deviation remained almost the same. As can be seen, the $\mathrm{CMD}$ was $2.0 \mu \mathrm{m}$ when rise distance was $3 \mathrm{~cm}$, yet the CMD became $2.9 \mu \mathrm{m}$ when rise distance went up to $7 \mathrm{~cm}$. This trend supported the above-mentioned postulation that large droplets had more time to get dried if the film rose high, and became aerodynamically small enough due to drying, and be carried into the test chamber.

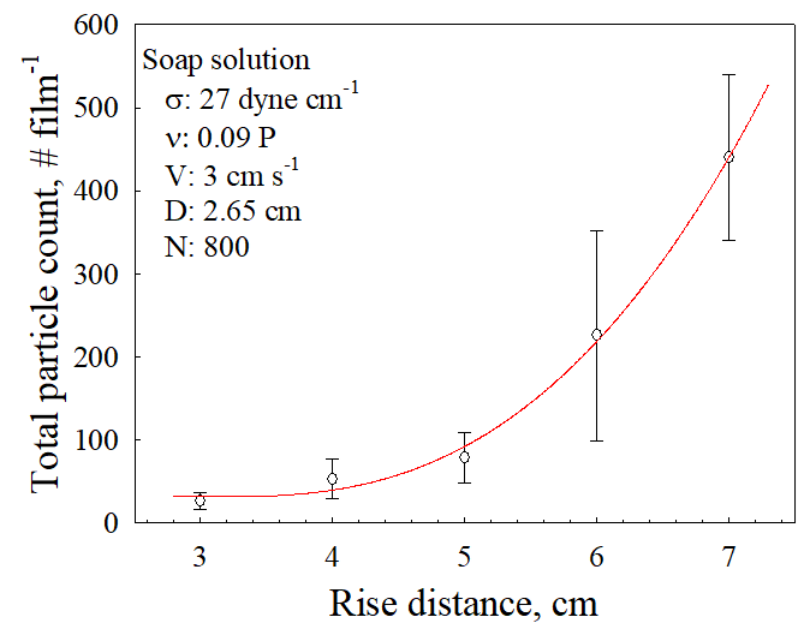

Fig. 5. Effect of rise distance on particle count generated from single-film bursting. Each error bar represents one standard deviation of 800 measurements.

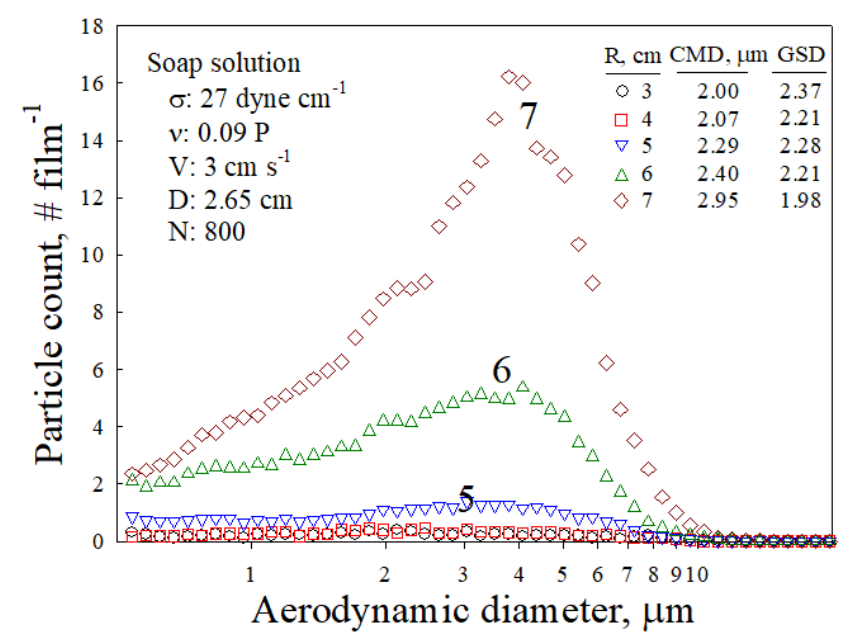

Fig. 6. Effect of rise distance on aerosol size distribution. 


\section{Effect of Rising Velocity on Single-film Aerosols}

Fig. 7 showed the total aerosol counts as a function of rising velocity for soap solution, surface tension of 27 dyne $\mathrm{cm}^{-1}$, viscosity of $0.09 \mathrm{P}$, and tube diameter of $2.65 \mathrm{~cm}$, rise distance of $7 \mathrm{~cm}$, and 800 replicates. The total aerosol count increased sharply from 20 to 440 \# film ${ }^{-1}$ when the rising velocity increased from 1 to $3 \mathrm{~cm} \mathrm{~s}^{-1}$, followed by a gradual decline with further increase in rising velocity. The increasing trend of the total aerosol count with low rising velocity was apparent because the rising draft carried more large droplets upward into the conditioning chamber to be measured by the aerosol instruments. The turning point at $3 \mathrm{~cm} \mathrm{~s}^{-1}$ was due to the clearer curvature of the film, as shown in Fig. 8. From the high-speed camera, the single film in the tube usually started to rupture right at or near the top center of the bubble. This was because the tube that holds the rising film stood vertically. Moreover, the film curvature forced the film liquid to drain to the tube wall, and the top part of the film thinned and became the starting point of bursting. Based on the time-resolved images, when the contact angle between film and wall kept decreasing, there were more droplets thrown onto the wall because of surface tension. The nature of the liquid film caused this deposition

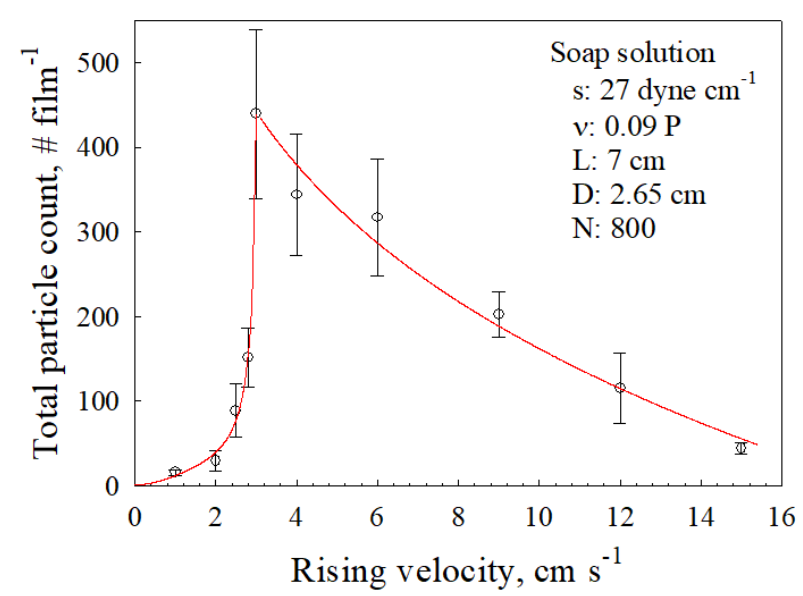

Fig. 7. Effect of rising velocity on particle count generated from single-film bursting. Each error bar represents one standard deviation of 800 measurements.
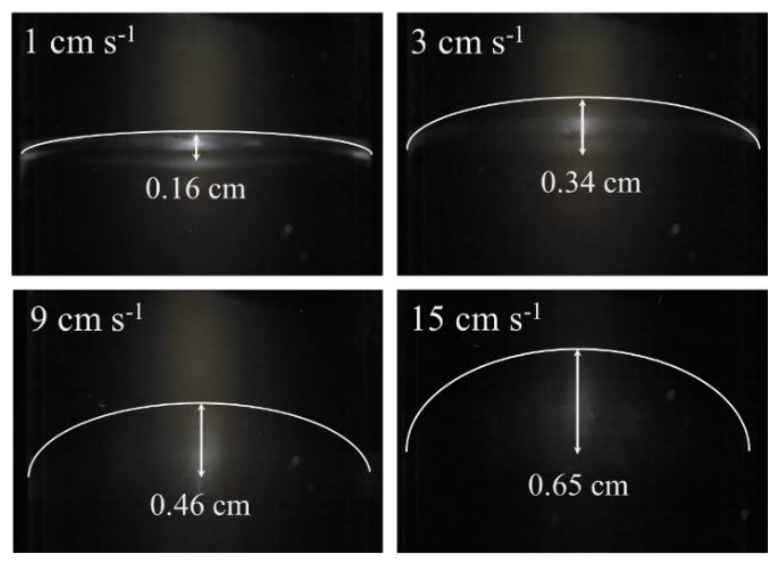

Fig. 8. Shape of film under different air velocities. loss to the wall, resulting in the lower aerosol count. This film curvature effect also modified the size distribution of aerosol particles measured downstream. The left plot of Fig. 9 showed an increase in both total number count and CMD when the rising velocity increased from 1 to $3 \mathrm{~cm} \mathrm{~s}^{-1}$. For rising velocity above $3 \mathrm{~cm} \mathrm{~s}^{-1}$, both total number count and CMD decreased with increasing rising velocity, as shown in the right plot of Fig. 9. This phenomenon was due to the increased curvature of the film with increasing rising velocity, causing more droplets from film bursting to deposit on the wall.

\section{Effect of Tube Diameter on Single-film Aerosols}

The effect of glass tube diameter on total aerosol count generated from single-film bursting is shown in Fig. 10. In theory, it takes more material to increase the strength of a film of larger diameter, i.e., a thicker film. Thus, in the case of soap solution, surface tension of $27 \mathrm{dyne} \mathrm{cm}^{-1}$, viscosity of $0.09 \mathrm{P}$, rising velocity of $12 \mathrm{~cm} \mathrm{~s}^{-1}$, rise distance of $7 \mathrm{~cm}$ and 800 replicates, the total aerosol count per film increased with increasing tube diameter, as shown in the upper plot of Fig. 10. However, when the total aerosol count was normalized to the surface area of the film, the total aerosol count per unit surface area became independent of tube diameter, as shown in the lower plot of Fig. 10. However, the film diameter has a strong effect on the size distribution of generated aerosols, as shown in Fig. 11, indicating that thicker film produces more and larger droplets after film rupture. For the same operating conditions of Fig. 10, the CMD increased apparently from $1.49 \mu \mathrm{m}$ for tube (film) diameter of $7 \mathrm{~mm}$ to $2.33 \mu \mathrm{m}$ for tube diameter of $29.4 \mathrm{~mm}$.

\section{Effect of Liquid Property on Single-film Aerosols}

The surface tension of the solution shows distinct influence on both total counts (Fig. 12) and size distribution (Fig. 13) of aerosol particles generated from film bursting. For the case of tube diameter of $2.65 \mathrm{~cm}$, rising velocity of $3 \mathrm{~cm} \mathrm{~s}^{-1}$, rise distance of $7 \mathrm{~cm}$, and 100 replicates, the total aerosol count decreased with increasing surface tension, as shown in Fig. 12. For the soap solution, the total aerosol count decreased from 400 to 10 \# film $^{-1}$ when the surface tension increased from 27 to 50 dyne $\mathrm{cm}^{-1}$. Mucus (surface tension ranging from 36 to 60 dyne $\mathrm{cm}^{-1}$ ) showed the same decreasing trend. The difference in the total aerosol count for overlapping range (surface tension between 36 and 50 dyne $\mathrm{cm}^{-1}$ ) is probably due to effects from other parameters, such as viscosity, and merits further investigation. Fig. 13 shows that the CMD generated from soap solution increased from 1.83 to $2.95 \mu \mathrm{m}$ when surface tension decreased from 50 to 27 dyne $\mathrm{cm}^{-1}$, while CMD of mucus aerosols increased from 1.55 to $2.56 \mu \mathrm{m}$ when the surface tension decreased from 60 to 36 dyne $\mathrm{cm}^{-1}$. These conflicting changes occurred because surface tension tends to keep the solution to the minimum surface area, i.e., a sphere. Therefore, for the same amount of solution, higher surface tension forms a lower number of larger droplets to maintain the least total surface area.

The surface tension of mucus in the respiratory tract normally ranges from 25 to 30 dyne $\mathrm{cm}^{-1}$ (Gehr et al., 1993; 


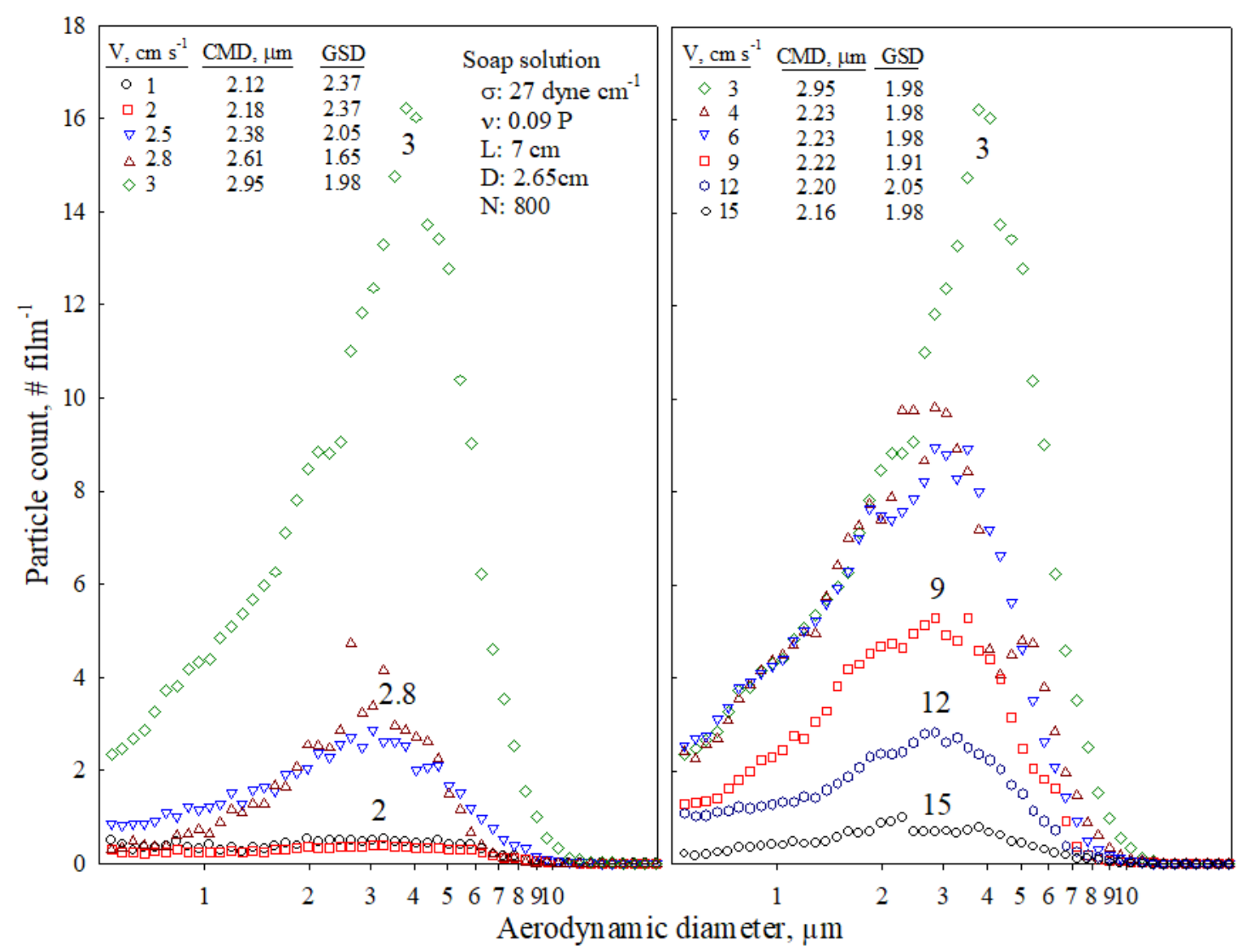

Fig. 9. Effect of rising velocity on aerosol size distribution.

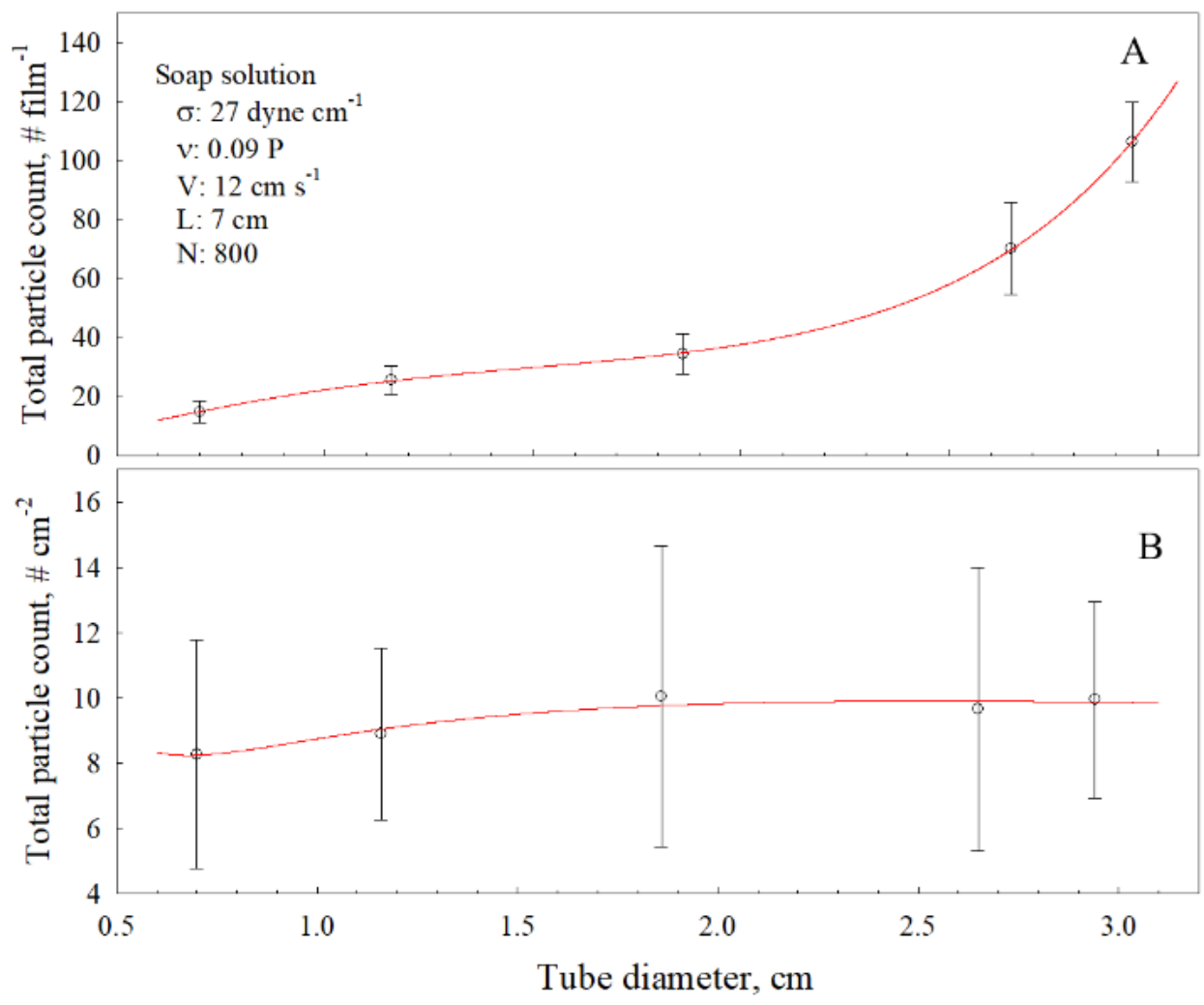

Fig. 10. Effect of glass tube diameter on particle count generated from single-film bursting. Each error bar represents one standard deviation of 800 measurements. 


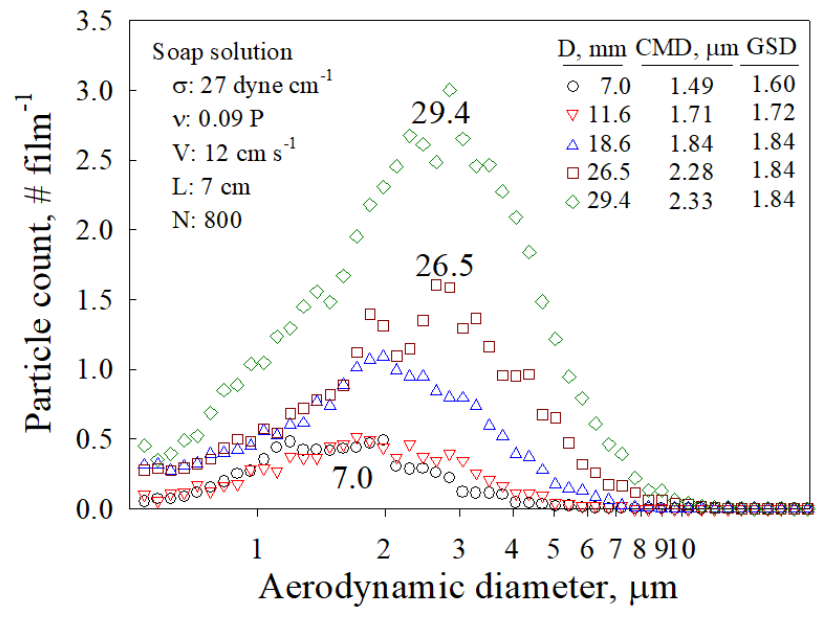

Fig. 11. Effect of glass tube diameter on aerosol size distribution.

Bernhard et al., 1997; Hohlfeld, 2002) and can be increased by adding a certain amount of saline solution to better simulate the actual situation in the respiratory tract. After adding $20 \mathrm{~cm}^{3}$ of saline to $50 \mathrm{~cm}^{3}$ artificial mucus, the

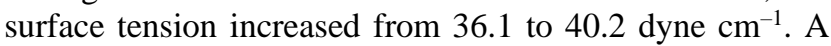
previous study reported a significant decrease in breath aerosols exhaled by subjects after inhaling saline mist for $6 \mathrm{~h}$ (Edwards et al., 2004), a phenomenon that agrees well with the results shown in Figs. 12 and 13.

The effect of viscosity on the total aerosol count from

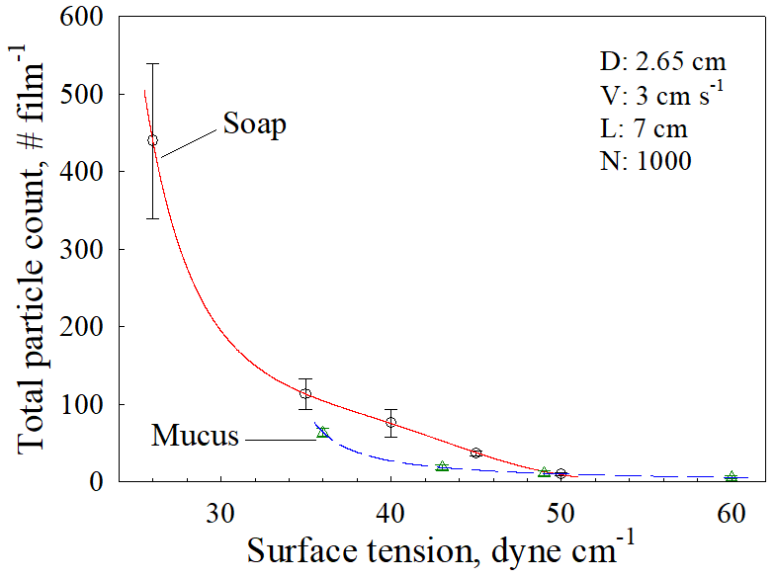

Fig. 12. Effect of surface tension on particle count generated from single-film bursting. Each error bar represents one standard deviation of 100 measurements.

single-film bursting is not obvious, as shown in Fig. 14, in which the viscosity of mucus varied from 0.45 to $3.45 \mathrm{P}$, with the surface tension fixed at 36.1 dyne $\mathrm{cm}^{-1}$, tube diameter of $2.65 \mathrm{~cm}$, rising velocity of $3 \mathrm{~cm} \mathrm{~s}^{-1}$, rise distance of $5 \mathrm{~cm}$, and 1000 replicates. Overall, surface tension and rising velocity are the two most influential factors affecting droplet formation from liquid film rupturing.

\section{Generation Mechanisms of Single-film Aerosols}

For the two aerosol instruments used in the present study,

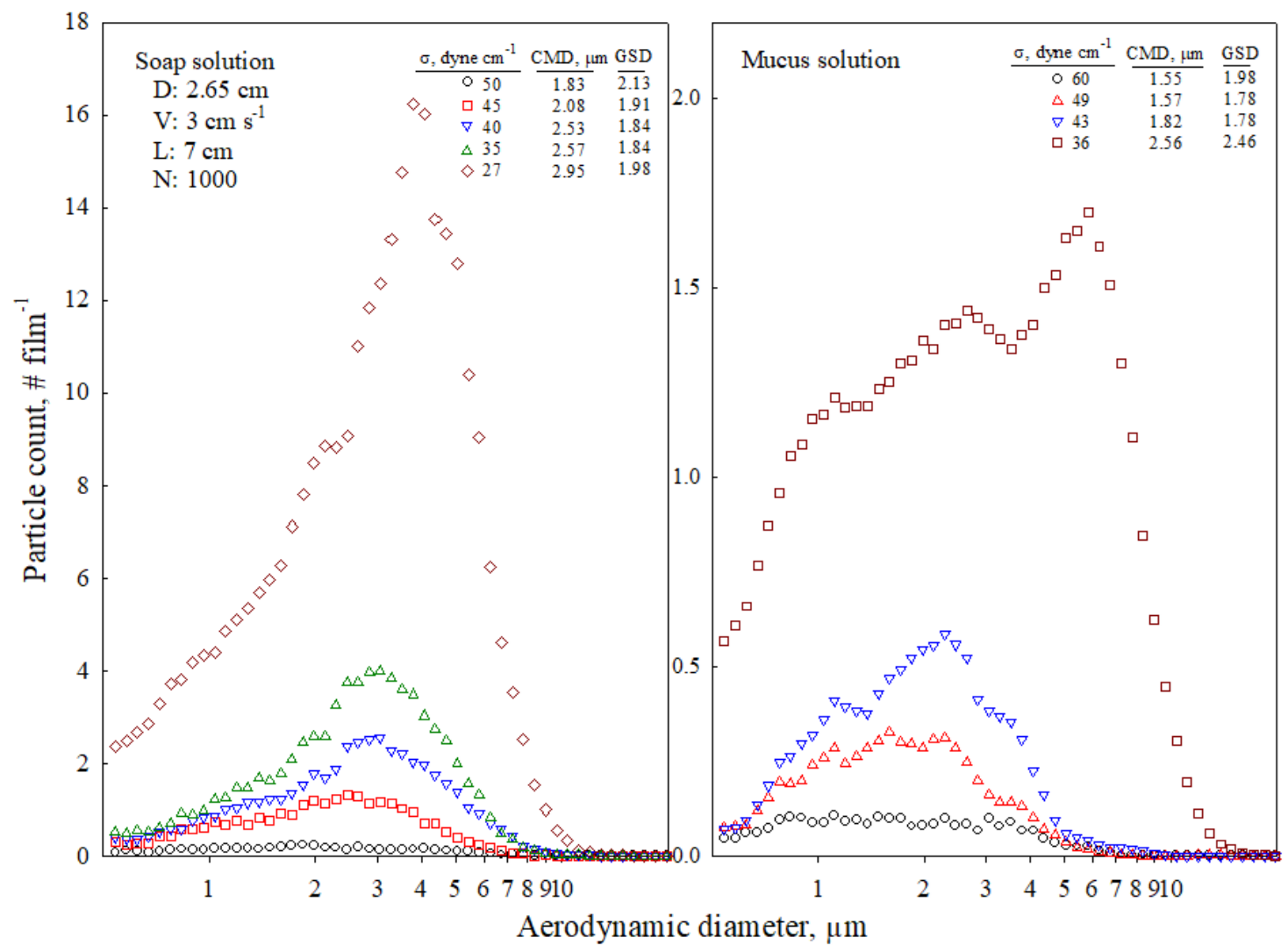

Fig. 13. Effect of surface tension on aerosol size distribution. 


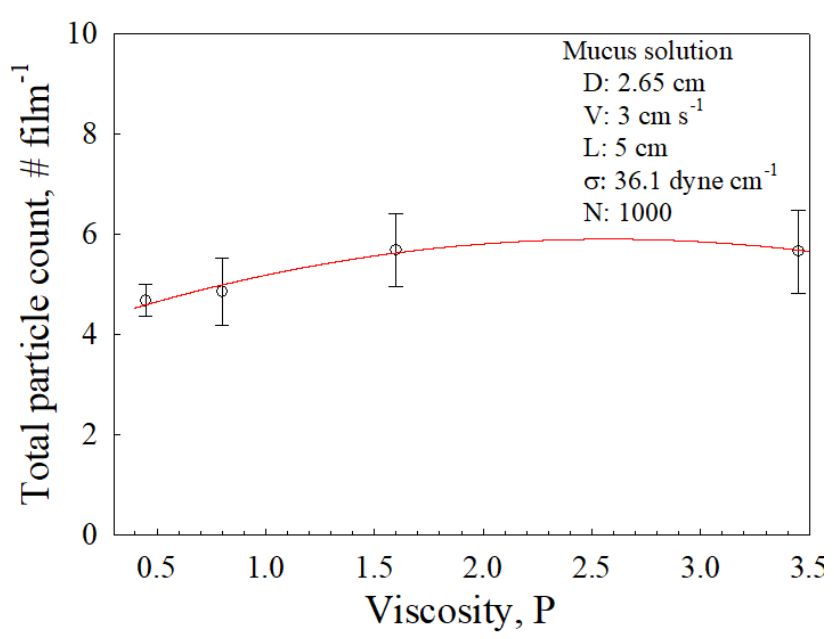

Fig. 14. Effect of viscosity on particle count generated from single-film bursting. Each error bar represents one standard deviation of 1000 measurements.

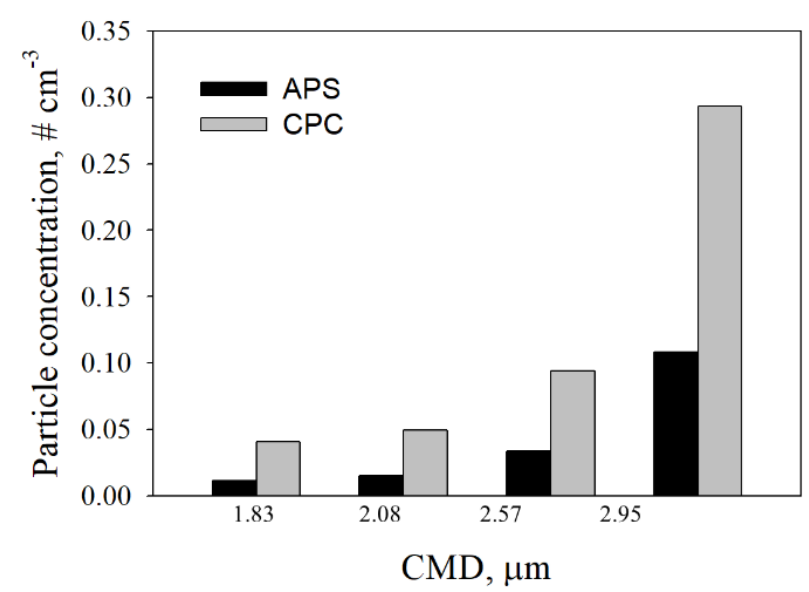

Fig. 15. Comparison of particle concentrations between APS and CPC.

the APS sizes aerosols from 0.6 to $20 \mu \mathrm{m}$, while the CPC counts only the number without sizing information. According to the ratio of total aerosol counts measured by CPC and APS, it is reasonable to infer that the aerosol particles generated from single film might have a bimodal distribution. As shown in Fig. 15, the APS count as the percentage the CPC count increased from $26.96 \%$ to $36.98 \%$ when the CMD increased from 1.83 to $2.95 \mu \mathrm{m}$. The increasing trend is probably due to a higher fraction of aerosol particles detected by the APS when the CMD is high. In other words, there might be a peak in the sub-micrometer size range, in addition to the peak measured by the APS. This inference would agree with a previous study showing that the coarse mode is due to film rupture while the fine mode is from the satellite droplet formation during the disintegration of liquid filaments generated from film breaking (Ke et al., 2017).

\section{CONCLUSIONS}

A single-film generation system was constructed to characterize the airborne particles produced by rupturing a film in a tube. The experimental system looked simple but involved complicated operations. The dwell time for generating a film needed to be longer than the purge time to avoid residual aerosols from the previously ruptured film. As expected, films that were larger in diameter required greater thickness for structural support and therefore generated larger aerosol particles. However, the generation rate expressed in terms of the unit surface area remained the same.

The total particle count increased with the rise distance because falling droplets had more time to dry out and be transported by the carrier air into the test chamber. Additionally, a longer rise distance resulted in a larger count median diameter. The number of particles also increased with the rising velocity, but only till the latter reached approximately $3 \mathrm{~cm} \mathrm{~s}^{-1}$, after which the trend reversed, with the number of particles gradually decreasing because of the film's increasing curvature and proximity to the wall (leading to potential particle deposition on the wall due to inertial impaction).

Surface tension played one of the most influential roles in the aerosol emission of both soap solution and artificial mucus. As the surface tension increased, the number of airborne particles decreased. Since adding saline solution increases the surface tension of mucus, thereby potentially lowering the total particle count, this method of reducing exhaled droplets may be considered in healthcare facilities. On the other hand, changes in viscosity exhibited almost no effect on the particle count.

Based on the ratio between the APS- and CPC-measured fractions, the airborne particles likely followed a bimodal size distribution, with twice the number of sub-micrometersized particles as micrometer-sized ones.

\section{ACKNOWLEDGMENTS}

The authors would like to thank Taiwan Ministry of Science and Technology for financial support of this study through grants MOST 107-3011-F-002-006 and MOST 107-2221-E-002-011.

\section{REFERENCES}

Afeti, G.M. and Resch, F.J. (1990). Distribution of the liquid aerosol produced from bursting bubbles in sea and distilled water. Tellus B 42: 378-384. https://doi.org/10.3 402/tellusb.v42i4.15232

Almstrand, A.C., Bake, B., Ljungström, E., Larsson, P., Bredberg, A., Mirgorodskaya, E. and Olin, A.C. (2010). Effect of airway opening on production of exhaled particles. J. Appl. Physiol. 108: 584-588. https://doi.org/ 10.1152/japplphysiol.00873.2009

Anwarul Hasan, M.D., Lange, C.F. and King, M.L. (2010). Effect of artificial mucus properties on the characteristics of airborne bioaerosol droplets generated during simulated coughing. J. Non-Newtonian Fluid Mech. 165: 1431-1441. https://doi.org/10.1016/j.jnnfm.2010.07.005

Bergeron, V. (1997). Disjoining pressures and film stability of alkyl trimethyl ammonium bromide foam films. Langmuir 
13: 3474-3482. https://doi.org/10.1021/la970004q

Bernhard, W., Haagsman, H.P., Tschernig, T., Poets, C.F., Postle, A.D., van Eijk, M.E. and von der Hardt, H. (1997). Conductive airway surfactant: surface-tension function, biochemical composition, and possible alveolar origin. Am. J. Respir. Cell Mol. Biol. 17: 41-50. https://doi.org/10.1165/ajrcmb.17.1.2594

Bird, J.C., de Ruiter, R., Courbin, L. and Stone, H.A. (2010). Daughter bubble cascades produced by folding of ruptured thin films. Nature 465: 759. https://doi.org/10.1 038/nature09069

Blanchard, D.C. and Syzdek, L.D. (1988). Film drop production as a function of bubble size. J. Geophys. Res. 93: 3649-3654. https://doi.org/10.1029/JC093iC04p03649

Champougny, L., Miguet, J., Henaff, R., Restagno, F., Boulogne, F. and Rio, E. (2018). Influence of evaporation on soap film rupture. Langmuir 34: 3221-3227. https://doi.org/10.1021/acs.langmuir.7b04235

Chao, C.Y.H., Wan, M.P., Morawska, L., Johnson, G.R., Ristovski, Z.D., Hargreaves, M., Mengersen, K., Corbett, S., Li, Y., Xie, X. and Katoshevski, D. (2009). Characterization of expiration air jets and droplet size distributions immediately at the mouth opening. J. Aerosol Sci. 40: 122133. https://doi.org/10.1016/j.jaerosci.2008.10.003

de Gennes, P.G. (2001). Some remarks on coalescence in emulsions or foams. Chem. Eng. Sci. 56: 5449-5450. https://doi.org/10.1016/S0009-2509(01)00170-1

Edwards, D.A., Man, J.C., Brand, P., Katstra, J.P., Sommerer, K., Stone, H.A., Nardell, E. and Scheuch, G. (2004). Inhaling to mitigate exhaled bioaerosols. PNAS 101: 17383-17388. https://doi.org/10.1073/pnas.0408159101

Espinosa, F.F. and Kamm, R.D. (1999). Bolus dispersal through the lungs in surfactant replacement therapy. $J$. Appl. Physiol. 86: 391-410. https://doi.org/10.1152/japp 1.1999.86.1.391

Fabian, P., McDevitt, J.J., DeHaan, W.H., Fung, R.O.P., Cowling, B.J., Chan, K.H., Leung, G.M. and Milton, D.K. (2008). Influenza virus in human exhaled breath: an observational study. PLoS One 3: e2691. https://doi.org/ 10.1371/journal.pone.0002691

Fabian, P., Brain, J., Houseman, E.A., Gern, J. and Milton, D.K. (2011). Origin of exhaled breath particles from healthy and human rhinovirus-infected subjects. $J$. Aerosol Med. Pulm. D 24: 137-147. https://doi.org/10.10 89/jamp.2010.0815

Gehr, P., Geiser, M., Hof, V.I., Schürch, S., Waber, U. and Baumann, M. (1993). Surfactant and inhaled particles in the conducting airways: Structural, stereological, and biophysical aspects. Microsc. Res. Tech. 26: 423-436. https://doi.org/10.1002/jemt.1070260510

Halpern, D., Jensen, O.E. and Grotberg, J.B. (1998). A theoretical study of surfactant and liquid delivery into the lung. J. Appl. Physiol. 85: 333-352. https://doi.org/10.11 52/jappl.1998.85.1.333

Hinds, W.C. (1999). Aerosol technology: Preperties, behavior, and measurment of airborne particles, (second edition), Wiley Interscience, New York.

Hohlfeld, J.M. (2002). The role of surfactant in asthma. Respir. Res. 3: 4. https://doi.org/10.1186/rr176
Holmgren, H., Ljungström, E., Almstrand, A.C., Bake, B. and Olin, A.C. (2010). Size distribution of exhaled particles in the range from 0.01 to $2.0 \mu \mathrm{m}$. J. Aerosol Sci. 41: 439 446. https://doi.org/10.1016/j.jaerosci.2010.02.011

Hung, H.F., Kuo, Y.M., Chien, C.C. and Chen, C.C. (2010). Use of floating balls for reducing bacterial aerosol emissions from aeration in wastewater treatment processes. J. Hazard. Mater. 175: 866-871. https://doi.org/10.1016/ j.jhazmat.2009.10.090

Ke, W.R., Kuo, Y.M., Lin, C.W., Huang, S.H. and Chen, C.C. (2017). Characterization of aerosol emissions from single bubble bursting. J. Aerosol Sci. 109: 1-12. https://doi.org/10.1016/j.jaerosci.2017.03.006

Kuo, Y.M. and Wang, C.S. (2002). Droplet fractionation of hexavalent chromium from bubbles bursting at liquid surfaces of chromic acid solutions. J. Aerosol Sci. 33: 297306. https://doi.org/10.1016/S0021-8502(01)00169-0

Lhuissier, H. and Villermaux, E. (2009). Bursting bubbles. Phys. Fluids 21: 091111. https://doi.org/10.1063/1.3200 933

Lhuissier, H. and Villermaux, E. (2012). Bursting bubble aerosols. J. Fluid Mech. 696: 5-44. https://doi.org/10.10 17/jfm.2011.418

Modini, R.L., Russell, L.M., Deane, G.B. and Stokes, M.D. (2013). Effect of soluble surfactant on bubble persistence and bubble-produced aerosol particles. J. Geophys. Res. 118: 1388-1400. https://doi.org/10.1002/jgrd.50186

Morawska, L., Johnson, G.R., Ristovski, Z.D., Hargreaves, M., Mengersen, K., Corbett, S., Chao, C.Y.H., Li, Y. and Katoshevski, D. (2009). Size distribution and sites of origin of droplets expelled from the human respiratory tract during expiratory activities. J. Aerosol Sci. 40: 256269. https://doi.org/10.1016/j.jaerosci.2008.11.002

Oldham, M.J. and Moss, O.R. (2019). Pores of Kohn: forgotten alveolar structures and potential source of aerosols in exhaled breath. J. Breath Res. 13: 021003. https://doi.org/10.1088/1752-7163/ab0524

Papinen, R.S. and Rosenthal, F.S. (1997). The size distribution of droplets in the exhaled breath of healthy human subjects. J. Aerosol Med. 10: 105-116. https://doi.org/10.1089/jam.1997.10.105

Pilacinski, W., Pan, M.J., Szewczyk, K.W., Lehtimäki, M. and Willeke, K. (1990). Aerosol release from aerated broths. Biotechnol. Bioeng. 36: 970-973. https://doi.org/ 10.1002/bit.260360913

Resch, F.J., Darrozes, J.S. and Afeti, G.M. (1986). Marine liquid aerosol production from bursting of air bubbles. $J$. Geophys. Res. 91: 1019-1029. https://doi.org/10.1029/JC $091 \mathrm{iC} 01 \mathrm{p} 01019$

Resch, F. and Afeti, G. (1991). Film drop distributions from bubbles bursting in seawater. J. Geophys. Res. 96: 10681-10688. https://doi.org/10.1029/91JC00433

Resch, F. and Afeti, G. (1992). Submicron film drop production by bubbles in seawater. J. Geophys. Res. 97: 3679-3683. https://doi.org/10.1029/91JC02961

Rio, E. and Biance, A.L. (2014). Thermodynamic and mechanical timescales involved in foam film rupture and liquid foam coalescence. Chem. Phys. Chem. 15: 36923707. https://doi.org/10.1002/cphc.201402195 
Russell, L.M. and Singh, E.G. (2006). Submicron salt particle production in bubble bursting. Aerosol Sci. Technol. 40: 664-671. https://doi.org/10.1080/02786820 600793951

Schwarz, K., Biller, H., Windt, H., Koch, W. and Hohlfeld, J.M. (2010). Characterization of exhaled particles from the healthy human lung-A systematic analysis in relation to pulmonary function variables. J. Aerosol Med. Pulm. D 23: 371-379. https://doi.org/10.1089/jamp.2009.0809

Spiel, D.E. (1998). On the births of film drops from bubbles bursting on seawater surfaces. J. Geophys. Res. 103: 24907-24918. https://doi.org/10.1029/98JC02233

Vrij, A. (1964). Light scattering by soap films. J. Colloid Sci. 19: 1-27. https://doi.org/10.1016/0095-8522(64)90003-0
Vrij, A. and Overbeek, J.T.G. (1968). Rupture of thin liquid films due to spontaneous fluctuations in thickness. J. Am. Chem. Soc. 90: 3074-3078. https://doi.org/10.1021/ja010 $14 \mathrm{a} 015$

Yeh, H.C. and Schum, G.M. (1980). Models of human lung airways and their application to inhaled particle deposition. Bull. Math. Biol. 42: 461-480. https://doi.org/ 10.1016/S0092-8240(80)80060-7

Received for review, October 29, 2020

Revised, April 7, 2020

Accepted, June 15, 2020 